\title{
Homo immunologicus: on the limits of critique
}

\author{
Andrew Goffey
}

\section{Correspondence to $\mathrm{Dr}$} Andrew Goffey, Department of Culture, Film, and Media, B38b Trent Building, University of Nottingham, Nottingham NG7 2RD, UK; andrew. goffey@nottingham.ac.uk

Received 20 December 2014 Revised 14 April 2015 Accepted 22 April 2015

\section{SLinked}

- http://dx.doi.org/10.1136/ medhum-2015-010695

\section{CrossMark}

To cite: Goffey A. Med Humanit 2015:41:8-13.

\section{ABSTRACT}

Through a discussion of a range of research drawn from the humanities and social sciences, and with a particular emphasis on work that tackles questions about the discourse of the life sciences, this paper considers some of the difficulties with research that aims to offer a critical analysis of immunology and its relationship to culture. It considers in particular arguments made on behalf of a biopolitical reading of the life sciences and, by examining the uncertain shift between discursive analysis and philosophical claim, it seeks to address some of the underlying assumptions made about the relations between different kinds of knowledge practice in the interplay between life science, philosophy and culture. Drawing on the work of Belgian philosopher of science Isabelle Stengers to consider the ways in which critical and philosophical appraisals of immunology adopt a characteristically modern stance in the way that they address the life sciences, it further seeks to characterise some of the limits that such forms of critique display.

\section{INTRODUCTION}

Critical interest in immunology, particularly evident in anthropology, philosophy, history and science studies, raises important questions about life sciences, the relationship between such research and the language used in its development, presentation and broader dissemination. Studies addressing the nature and significance of developments in immunology ${ }^{1-3}$ have done much to draw our attention to the cultural resonances of immunological discourse. This critical work has furthered our understanding of the problematic ways in which immunology's understanding of the vertebrate organism's response to pathogens dials into a complex array of heavily loaded cultural metaphors, metaphors that typically work to skew explanations towards historically partial and culturally particular understandings of sickness. Further, the extraordinarily high profile of AIDS, the problematic quality of governmental responses to it (eg, in South Africa ${ }^{4}$ ), along with the growing awareness of the lacuna in scientific understandings of illness associated with problems of autoimmunity, have also been of central importance. More recent explorations of difficulties in broader understandings of identity raised by autoimmune diseases have led one recent commentary to refer to an 'immunological turn' in thinking. ${ }^{5}$ Going beyond a strict focus on scientific research as such and encompassing more philosophically informed explorations of immunity, the writings of, amongst others, Luhmann, ${ }^{6}$ Derrida $^{7}{ }^{8}$ and Esposito ${ }^{9}$ have been especially prominent in this 'turn', treating immunology as a significant conceptual resource for developing an account of important features of the contemporary social and political landscape. Although philosophical appropriations of immunology can easily be faulted for a lack of attention to the detailed findings of scientists, overlooking the links between philosophy and science is not so easy in the case of immunology. Anderson and Mackay have made this point aptly, reminding us of Sir Frank Macfarlane Burnet's remark that "immunology has always seemed to me more a problem in philosophy than a practical science". ${ }^{5}$

This paper explores some of the issues that this supposed 'immunological turn' raises with regard to the links between science, philosophy and culture. It does so with a view to opening up a question about how one might do critically informed medical humanities research in the light of what it sees as two equally problematic understandings of science. Critical research has done much to contest unproblematically realist understandings of science, understandings that reinforce an image of an autonomous scientific rationality having access to the world in a way that guarantees knowledge (rather than the mere beliefs of nonscientific others). But it often does so only by offering a view of science as the enemy to be contested: science as a construction of dominant economic, social or political interests, or vector of a broader instrumental rationale, science as pretending to a privileged status that belies its quality of being a practice 'just like any other'. In this regard, navigating between the Charybdis of "those who identify 'Science' with the conquest of a knowledge of reality that is finally objective" and the Scylla of "those who identify it with a conquering power against which it is a matter of struggling" (p. 56) has been one of the merits of Belgian philosopher of science, Isabelle Stengers. This paper draws on some of Stengers' insights regarding the problematic qualities of modern rationality in order to consider the complex interplay between science, philosophy and culture that is operative within such work. It considers some of the ways in which perfectly justified concerns with the broader implications of immunological discourse exemplify what Stengers see as one of the favourite 'vices' of our tradition. This vice is, as she puts it, "to construct a perfectly convincing argument that, as if by chance, has the capacity to dissimulate or condemn a question that it doesn't feel very certain about". ${ }^{11}$ A classic example of such a vice might be found in the history of the explaining away of the complex phenomenon of hypnosis through catch-all terms like 'suggestibility'. ${ }^{12}$ In this respect, the paper is concerned as much with the way that relations between knowledge practices are implied in the form in which arguments about immunology are made as it is with the substantive findings of critical accounts of immunology themselves. 


\section{MOBILISING THE TROPES: IMMUNOLOGY AND CULTURE}

Emerging out of the founding work at the end of the 19th century of figures, such as Elie Metchnikoff, a Russian émigré working in Paris, and Robert Erlich, in Germany, working as a pupil of Robert Koch, immunology sought to understand the vertebrate organism's apparently rather magical capacity to discriminate between those substances that are harmful and those that are not harmful to it and to mount responses to those that are. ${ }^{13} 14$ Whilst Metchnikoff proposed a sort of cellular theory of immunity that concentrated on the role of phagocytes, Erlich, whose stance is often described as 'humoralist', gained the ascendency, initiating an approach to questions of immunity that effectively addressed the mechanics of recognition at a chemical level. In this respect, his work and the subsequent 'immuno-chemical' stance found congruence with the emerging reductionist explanatory strategies that dominated in the life sciences in the early 20th century (and still do, in many respects). Explanations of immune phenomena that focused on issues to do with the stereospecificity of antibody-antigen relations were compatible with the emerging field of molecular biology, with Linus Pauling at CalTech in the States having a key role to play in linking immunochemistry with molecular biology. ${ }^{14-16}$ Much work in immunology in the 20th century tended to presume that the immune system served the purposes of protecting an identity defined independently of its own functioning, a position that the humoralist-and then molecular biological approaches tended to reinforce. In some respects, though, as philosopher and historian of science Alfred Tauber has pointed out, in several of his philosophically oriented reconstructions of the historical development of immunology, ${ }^{14} 17$ Metchnikoff forms an interesting counterpoint to this tradition because his work tends to imply that the immune system is constitutive of identity, not primarily protective of it. This is a stance that has gained much ground in ulterior developments such as those of Nils Jerne, whose 'idiotypic network' theory of immunity moved towards seeing immunity in more systemic terms as an ongoing self-regulating homeostatic process (rather than as something focused primarily on response to 'insult'). ${ }^{15}$

It is the aggressively imagistic language of security and warfare, which runs throughout the historical development of immunology, that has proved of most interest to critical researchers. The long history of that language use itself is somewhat complicated, though, and it is important to acknowledge that it is not just immunology that has had recourse to martial metaphors in its understanding of biological processes. We can, for example, find in the writings of Cotton Mather, accredited, like Jenner, with the discovery of the efficacy of inoculation, a comparable vocabulary, in a text that preceded Metchnikoff by some 160 years. Discussing the effectiveness of smallpox inoculation, in The Angel of Bethesda, Mather writes of smallpox as an 'enemy', the body as a 'citadel', of 'spoils', 'assaults', 'combat', 'surrender', 'invaders' and so on (p. 112). ${ }^{18}$ But we can also find a similar kind of vocabulary employed in life sciences research in the 19th century more broadly. Virchow, for example, spoke of the police state in relation to the organism (with the phagocyte as its 'gendarme') as early as 1848 . The German translation of Darwin's expression 'the struggle for existence' as a 'Kampf'-both a struggle and a battle-was consecrated in embryologist Wilhelm Roux's study Der Kampf der Teile im Organismus in 1881, several years before Metchnikoff began to refer to the idea of 'den Kampf der Phagocyten gegen Krankheitserrger'. And crucially perhaps, this martial language is not simply a lurid historical artefact. For example, whilst written for a non-specialist audience, Marion Kendall's work ${ }^{19}$
Dying to Live: How Our Bodies Fight Disease is exemplary of the genre, describing immunological processes in terms of repelling invaders, major defences, subversive agents, general defence policy, sentry duty, the weapons of war, the critical battle and so on. Similarly, Nilsson and Lindberg's 1987 book, The Body Victorious, does not hesitate in referring to "highly mobile regiments, shock troops, snipers, and tanks" ${ }^{20}$ in its account of the immune system.

For critical research, this mobilisation of tropes raises important questions. Given the preceding, Burnet, a central figure in mid-20th-century immunology, can hardly be described as breaking the discursive mould in his references to antibodies as 'plain-clothes detectives with perfect memories for criminal faces' ${ }^{21}$ for example. But when considered more closely, in relation to the ambient research of his day-in cybernetics and communications, key elements of science emerging out of the Cold War military industrial complex-Donna Haraway's characterisation of his work as an 'operations research approach to biology',22 is an apt descriptor of the more historically precise ways in which the military/securitarian language of immunology can be contextually situated. What one finds in Burnet's midcentury research is a translation of "an older militaristic discourse on defense and attack into the new language of control, communication, recognition, tolerance, and surveillance" (p. 158), ${ }^{5}$ a language that, when recontextualised, appears to be closely tied to the geopolitical agenda of the USA. Although Burnet had used the language of ecology in his research, the broader point is that a closer reading of the language of life sciences research exemplifies the ways in which the Cold War military industrial imperatives infected the conceptual apparatus for the production of understandings of the bodies.

Addressing the issue of the contextual specificity of the language of immunology is something that has proved an enduring concern for critical research into the cultural functioning of the life sciences. By the 1980s, Haraway suggests, immunological discourse in the US bore significant figurative resemblances to the military-industrial strategic defence initiative, but with the significantly racially inflected trope of the 'space invader' pointing towards the updated but nonetheless significant presence of the 'tones of colonial discourse' (p. 223) ${ }^{1}$ within the language of science. Because selfhood and individuality are interpreted in terms of a particular set of biological capacities that are articulated through the militaristic and racially inflected language of war mentioned already, Haraway argues that immunology offers a potent resource, for "mediating the experience of sickness and death for industrial and post-industrial peoples", 1 and makes the body, as constructed through immunology, something of a contested terrain.

Appropriately contextualised, the figurative resonances of the language of immunology go beyond operating as a relay of military-industrial imperatives. Emily Martin's study of the 'co-construction' of the immune system within American culture, and specifically by the media, as the findings of scientists move out of their laboratories is exemplary in this regard. Amongst other features of the language of immunology noted by Martin (in addition to those picked up on by Haraway) is its gender coding: if non-self equates to aliens who do not speak the immune system's language, the work of the immune system itself follows a gender hierarchy-macrophages as housekeepers, B-cells as a kind of 'upper-class female', with T-cells at the top as the system's battle commanders (p. 57). ${ }^{2}$ Thus, the critical interest in the 'body at war' understanding of the immune system can be extended into a more specific exploration of its congruence with shifts in the organisation of the division of 
labour: the work of Nils Jerne, for example, and his theorisation of immune processes in terms of the concept of the idiotypic network is linked to the emergent re-organisation of economic practices around the notion of 'flexible specialisation' (p. 104). ${ }^{2}$

A key concern for critically informed anthropologists and science studies scholars with regard to the language of immunology, then, has to do with the ways in which cultural understandings- of the self, the body, of the experience of sickness and death, are not just constructed through scientific discourse, but relayed through other discourses too. When contextualised in relation to broader discursive patterns such as those of Cold War rhetoric, these constructions can start to be seen as problematic-suggestive of a link between scientific research and broader political agendas, naturalising historically and cultural specific worldviews. However, it is probably true to say that there is not much consensus on how to contextualise immunological discourse, in relation to what other aspects of culture, and this can in turn have consequences for the claims that can be made. For example, for A. David Napier, linking immunology to a broad anthropological understanding of cultures, rather than to the more historically specific situation of late Cold War America, leads to a view of immunology that renders it very little different from a form of demonology pure and simple, engaged in generating and reinforcing a cultural understanding in which the "the attempted elimination of the internalised 'other' is projected everywhere" (p. 3). "Exploring the science of immunology in a such a context, for Napier, is to reveal the ways in which a domain of esoteric [scientific] knowledge is dependent on the same cultural values that are everywhere else at work" (p. 4, my emphasis). ${ }^{3}$ In this respect immunology translates a broader and continually reinforced attempt to protect ourselves from "transformational encounters with 'otherness"' (p. 7) ${ }^{3}$ and thus to maintain the geopolitical privilege of the colonial position. This finding is congruent with the claims of Haraway and Martin but it starts out from different premises.

\section{BIOPOLITICS: IMMUNITY AS A HISTORICAL PROBLEM}

Critical research into immunology often acknowledges the complexities of the contexts in which it is situated-Haraway, for example, pointing to a whole 'apparatus of bodily production' in which the world is not simply there 'waiting only to be read' but in which bodies themselves have an active role to play. Cambrosio and Keating's ${ }^{23}$ work on 'biomedical platforms', with its discussion of immunophenotyping, tallies well with Haraway's account on the practical construction of scientific knowledge-and her appeal to the 'material-semiotic agency' of bodies is indicative of a commitment not to reduce the world to discourse. However, it can be the case that critical research exploring immunological discourse forgets, or perhaps strategically overlooks this issue. By considering more carefully some of the ways in which these kinds of critical readings operate here, which are often conceptually very sophisticated, we can get a better sense of how critical approaches to immunology themselves start to replicate the kind of problems that Stengers associates with 'our' tradition.

The turn to discourse, to text, or to rhetoric (the three not always being particularly clearly distinguished) has been a characteristic of much work on the cultural shaping of life scientific knowledge. The historical work of Michel Foucault has proved doubly useful-both substantively and methodologically-in this regard. On the one hand, his emphasis on discourse and its 'anonymous' rules of production has provided a powerful tool for addressing the historical specificity of forms of knowledge (eg, a point acknowledged by François Jacob). ${ }^{24}$ On the other hand, his conceptualisation of biopolitics as a peculiarly modern power-knowledge formation has been invaluable for understanding some of the links between research in the life sciences and modern practices of government and the organisation of power.

For example, Melinda Cooper's suggestive account of the place of biotechnology and the life sciences in the turn of the century reorganisation of capitalism ${ }^{25}$ builds both on the substance of Foucault's analyses of parallel transitions in both the life sciences and classical political economy, as well as his 'archaeological' approach to discourse, to arrive-in relation to immunology - at somewhat similar conclusions both to Haraway and Martin. Noting the connections between the "welfarist ideal of normalized nation-centred growth" and public health, she argues that "the mid-twentieth century theory of immunity concurs with the philosophy of the nation-state that threats are always identifiable and peace, in principle, attainable" (pp. 61-2). ${ }^{25}$ Pointing to what she sees as the "conceptual affinity' (p. 62) between biological and political immunity she suggests that the emergence of the neoliberal rethinking of risk is accompanied by a "a profound rethinking of the dominant twentieth century ideas about biological defense and resistance..." (p. 62) $)^{25}$ a historical connection that subverts any sense that scientific and economic discourse are ultimately separate.

The apparent 'conceptual affinity' between theories of biological and political immunity has proved most intriguing to researchers interested in developing a critical analysis of immunological discourse in terms of the biopolitical problematic. The interest here is not so much one of exploring the ways in which scientific research findings are mediated across culture, but of bringing to light the intrinsically problematic framework within which life science research operates. This offers a somewhat different way of considering the congruences-in Cooper's terms, the 'conceptual affinities'-between immunology and other kinds of discourse: a concurrent inscription within the same 'epistemic' framework, the same historically a priori set of discursive rules.

Approaching immunology through a 'biopolitical' analytic facilitates a more extensive exploration of the links between life science research and broader historical shifts. Pointing to the legal and political origins of terms like 'immunity' and concepts like 'self-defence' Cohen has argued that we can trace the 'immunity-as-defence' understanding of the body and its capacities to the presence on the European continent of a series of internecine wars and the changing status of the human population as a bulwark of territorial defence in the 19th century in particular. In this respect, to understand what is problematic about immunology requires a genealogical exploration of this broader reconstitution of the status of the human body. As Cohen puts it, "the disciplinary formation of the natural body bespeaks the escalating incorporation of war in the mundane ways we live" (p. 20). ${ }^{26}$ Situated historically in this broader disciplinary formation, the use of a language derived from law and politics as a way to describe the natural functioning of the organism becomes less mysterious. Cohen sees immunology as accomplishing a fusion of military, political and biological thinking, in which framework it "establishes war-at the level of cells and molecules-as the condition of life itself" (p. 20). ${ }^{26}$

A similar, but more hermeneutically inflected account of the provenance of the term 'immunitas' and a historically deepened study of the connections of immunology with biopolitics is to be found in Roberto Esposito's work. ${ }^{9}$ This work develops an account of the biopolitical qualities of life science research 
through an extension and refinement of a claim made by Niklas Luhmann, regarding the historical migration of the semantics of immunity from law to all spheres of society in the 18th century. However, where Luhmann sees in this migration something that is neutral, ${ }^{6}$ Esposito sees something rather different. Tracing out the connections between a series of apparently disparate phenomena-outbreaks of disease, changes in the rate of flow of migration, tampering with a communications system and so on - he argues that it is the process of immunisation, the process of protecting through negation, that unites such phenomena. Immunisation, in his view, is the "symbolic and material lynchpin around which our social systems rotate" (p. 2). ${ }^{9}$ Esposito reads immunisation as a generalisable "homeopathic protection practice" that extends across the natural and cultural spheres, disclosing in turn a fundamental but hitherto unthought aporia in "all the languages of modernity", in terms of which 'immunitary logic' "can prolong life, but only by continuously giving it a taste of death" (p. 9). ${ }^{9}$ Immunology ceases to be a merely scientific discourse but offers a way of thinking the ways in which the bare biological life of the organism becomes the focus of investment of power and politics and the overlap between the legal/political and biomedical fields within which immunity operates as a concept can be traced back to obscure features of Roman law. ${ }^{9}$ Evidently, as these cursory summaries suggest, offering an adequate critical account of immunology within a biopolitical framework moves us away from a strict focus on scientific findings, indeed it quickly becomes a shift into philosophy. For Esposito, for example, this is quite explicit, as he claims that the problematic semantics of immunity forms the 'transcendental conditions' for the understanding of all social institutions. $^{9}$

\section{HOMO IMMUNOLOGICUS}

The shift from life science research into philosophy is not surprising. Nor should it be considered in and of itself a bad thing, even if it might be something in which immunologists do not have that much interest. As was noted earlier-with reference to Burnet-immunity in some respects does indeed represent a philosophical rather than a scientific problem. But the key question, of course, is in what sense? Burnet's stated aim-to avoid slipping into the incoherence of ad hoc hypotheses-clearly expresses the concern of a practitioner endeavouring to make sense out of a puzzling array of findings, and, externally contextualised explanations aside, his solution, relating to the idea of immunology as the science of self-non-self distinction, quite clearly found resonances within the research community of which he was a part. Biopolitical accounts of immunology are also in search of a coherence, but one of a rather different kind. In the examples considered, the language of immunology is read as an important constituent component of the operation of a specific form of politics, understood to have emerged historically in a determinable relation to life scientific knowledge practices: it helps make sense out of this politics. But what is most striking about these accounts is that scientific research comes to embody a problem of which its practitioners must, almost by definition, be unaware. Framed historically in terms of 'transcendental conditions', as it is with Esposito or, in a more explicitly Foucauldian way, in terms of 'epistemes', the biopolitical problematic tends to address the historical 'conditions of possibility' of immunology as such. In this way, critical research is addressed to something that cannot concern immunologists as immunologists: what their practice presupposes.

Equally striking here is the inordinate importance given to immunology in the broader historical view of things. A world might separate the historical scope of Esposito's hermeneutics or Cohen's deconstruction from the meticulous 'internalist' work of Alfred Tauber or the sweeping narrative of Enlightenment in the work of philosopher Peter Sloterdijk; nonetheless, there is a strange knotting together of philosophy and science across all this work, despite the significant differences in the way that immunology is understood and critique employed. The point here is not a substantive one regarding biopolitics. Rather it is an issue about the propriety of interpreting immunology and philosophy as exemplary explorations of a shared problem. Tauber's work goes beyond the remit of reading the development of immunology in terms of the early conflict between reductionist and holist explanatory strategies (Ehrlich vs Metchnikov). He insists on the importance of situating the emergence of immunology in relation to a fin de siècle search for identity, and on associating immunology with the intellectual drama—some might say crisis—of Western modernity itself. Exploring immunology, the twists and turns of its discoveries, difficulties and dilemmas, in the context of a broader set of connections with what he sees as a philosophical striving for the truth of identity, he builds on his work with Leon Chernyak to argue that "to define the self has become immunology's primary mission, the ultimate puzzle for the science that is attempting to identify the organism" (p. 295). ${ }^{14}$ In this account, immunology is read in tandem with philosophy, with a figure like Burnet being read as a kind of immunological equivalent of a Kant in his concern to argue that all knowledge presupposes an underlying subject. Immunology in turn is seen as offering a more plausible grounding for the kinds of 'a prioris' that Kant made so central to his own arguments, thereby offering scientific confirmation of a philosophical idea. Tauber's view is that it is only in terms of this broader, shared, problem that sense can be made of what it is that immunology is aiming to do.

The very central place that immunology thereby acquires in modernity receives hyperbolic confirmation in Sloterdijk's arguments about 'homo immunologicus'. Central to his interest in 'anthropotechnics' and the production of the human 'by the human', homo immunologicus provides Sloterdijk with something of a dramatic figure for a narrative that employs immunity as a general concept to understand the ways in which cultural practices confer protection on individuals and groups. What is interesting about Sloterdijk's account (which has little to do with immunology per se) is the power that Sloterdijk attributes to the discoveries of immunological research. As he puts it "among the wealth of cognitive novelties under the modern sun, none are remotely comparable in their far-reaching consequences to the appearance and propagation of immune systems in the biology of the late nineteenth century" (p. 7). ${ }^{27}$ Immune systems thinking offers Sloterdijk a means to develop a general account of socially and culturally generated immunity, with symbolic frameworks understood in terms of "the methods of mental and physical practicing by which humans from the most diverse cultures have attempted to optimize their cosmic and immunological status in the face of vague risks of living and acute certainties of death" (p. 10). ${ }^{27}$

These two otherwise very different ways of looking at immunology share several characteristics. The first is that they concur in giving immunology pride of place in addressing philosophical problems, indeed in finding that immunology addresses problems with a remit that goes way beyond the specific findings of scientific research. In this respect-and this is the second point-they both, in very different ways, ascribe a peculiarly critical importance to immunology (albeit in a different sense from the theorists of biopolitics). For Sloterdijk, the value of the 
findings of immunology is that it allows him to propose a 'biocultural' or 'bio-social' explanation of, for example, religious practices. Far from being about beliefs, religious practices, when interpreted in the light of immunology, function symbolically as part of the diverse set of "methods of mental and physical practicing by which humans from the most diverse cultures have attempted to optimize their cosmic and immunological status in the face of vague risks of living and acute certainties of death" (p. 10). ${ }^{27}$ In this respect, Sloterdijk sees immunology as prolonging the Enlightenment-critical move of shaking people out of their illusions, of knowing where others believe (although his is a rather loose extension of its discoveries): immunology explains the functioning of religious practices without the need for a surreptitious appeal to dualisms of the nature/culture kind. Similarly, Tauber, whilst scrupulous in his reading of the back and forth movement between metaphor and theory in immunology, discovers in its concerns the critical capacity to provide a truth where philosophy had ultimately perceived only metaphor. In both these respects, immunology is seen to provide a truth where other forms of enquiry had failed.

Reading between the lines of these accounts, the truths that they uncover are what we might call characteristically 'modern' truths, truths that are implicitly or explicitly accorded with the power to judge others, a power to disqualify the questions that others might seek to ask. Viewed in this way, the central role accorded to immunology in the work of Tauber and Sloterdijk exemplifies the politics of modern knowledge practices, those practices that in the account proposed of them by Isabelle Stengers, create or presuppose a "great political division between scientific practice and opinion" (p. 65), ${ }^{11}$ that then operates to disqualify other kinds of thinking. So, with regard to religion (in Sloterdijk's case) we might say "immunology now explains why we were previously wrong about religion”, or with regard to philosophy (in Tauber's case) "where you philosophers thought that the self was a mere play of language, immunology now shows us that it has a biological basis" and so on. The ironic quality of modern knowledge practices is thereby exhibited, whereby practices are caught up in a movement that constantly opposes truths of one sort with truths of another with a greater power. The recurrence of this movement and the antagonisms that result from it, which often fuel disputes between the sciences and the humanities, the humanities and the social sciences, or philosophy and literature, raises a significant question for a critical medical humanities. What, in short, are the prospects of knowledge practices that seem destined constantly to speak over one another's heads through 'reduction' (ie, via the construction of truths endowed with the capacity to say: "Your $\mathrm{X}$ - a sunset or a sincere declaration of love, for example - is really only a Y [electromagnetic radiation, a strategy to maximize genetic replication]) learning to talk to each other in ways that don't simply ratify this ironic capacity for judgement?”

\section{DISCUSSION}

Tauber and Sloterdijk's work on immunology is evidently different not just in its evaluation of life sciences research (positive, rather than negative) but in the links between science, philosophy and culture these evaluations imply, to the other kinds of critical engagement that have been addressed here. Yet considered in terms of Stengers' reading of modern knowledge practices, there is much greater proximity than might at first appear to be the case, because the more obviously critical readings of life science research also eventuate in the construction of 'ironic' truths.

Critical approaches to science that consider science as culture (ie, as an activity that is not radically autonomous of a range of historical, political, social factors) rightly remind us that scientific practices can be considered cultural activities much like any other. Yet calling into question the presumption of an exceptional status-by drawing attention, for example, to the ways in which scientific language is replete with historically specifiable tropes, for example-runs a number of risks. Whilst exploring the social and cultural significance of immunology in terms of its evident employment of martial metaphor does not necessarily amount to reducing immunology to a text or a discourse, it does suggest that what matters in it politically is what can be reduced to and considered as part of a broader social and/or cultural construction. This appears to be the case for Napier, for example, finding a culture-wide set of values at work in immunology that renders its otherwise esoteric knowledge culturally decodable, and a privileged form of evidence for a condition to which 'we' are all subject. Reading science more broadly in terms of its employment of metaphor can equally prove problematic, particularly if it results in the reduction of science to text or discourse. This is a point that, interestingly, Haraway was quick to point towards in her own work. Using 'Coyote' a figure from American Southwest Indian culture to refer to the immune system, she suggests that neither the latter "nor any other of bio-medicine's world-changing bodies-like a virus-is a ghostly fantasy. Coyote is not a ghost, merely a protean trickster" (p. 209)..$^{1}$ The more general point is not that one should ignore the problematic operation of metaphor, or the links between immunological discourse and political discourse. Rather, it is to say that critiquing traditional, unsituated accounts of scientific realism does not, or should not, slide into the solely cultural, solely socially constructed view of knowledge practices. Scientific practices are unavoidably cultural practices, but they also have a singularity that demands exploration.

The more philosophical elements of the turn towards discourse in critical studies of the life sciences, associated specifically with arguments that address immunology in terms of biopolitics, complicate the difficulty that Haraway is taking issue with. For when hermeneutic or discursive arguments are considered in terms of 'transcendental conditions', one cannot simply appeal to the realism that says that the world and the bodies in it can challenge our claims to knowledge. This is because-so the argument would run-meaningful discourse is presupposed in any reference to external reality in scientific practice: one simply can never escape discourse. There is a powerful rationale for approaching life science research through a focus on its language (however conceptualised). More than a simple methodological justification relating to one's research material, the point is a substantive one about practices as such: all practices are, in some way or another, discursive practices. The more philosophical appeal-explicit in the case of Esposito, tacit in the Foucauldian framework of other research-to transcendental conditions, or (historical) a prioris, has a further consequence: it shifts the appeal to generality onto a ground that it is difficult to challenge from within life scientific practice because it is seen as being the ground of that practice.

Stengers proposes that because of the 'power' that accrues to the kind of general truth claim that is embodied within arguments about transcendental conditions or a prioris, we should talk instead about the constraints that scientific and other practices have to address. A constraint, in her view, "must be satisfied, but the way it is satisfied remains, by definition, an open question" (p. 43). ${ }^{28}$ Language is one element of scientific research practices but far from being the only one. Considered in terms of constraints, rather than conditions, general problems about the meanings of words like 'immunity' have little purchase on the 
specific ways in which immunology captures or is captured by language, because the catch-all nature of such generalities means one knows in advance how this constraint, seen to be primordial, is satisfied in practice-in the same way as any other.

The key point is to challenge the abstractedly general understanding of scientific knowledge that has largely prevailed in the philosophy of science, and which is replicated across other disciplines. For Stengers, what makes the experimental sciences valuable, for example, is not the way that they offer an all-terrain mathematico-statistical way of developing reliable knowledge of the world, but rather their singular inventiveness in constructing laboratory artefacts that resist all the tests that are imposed on them to expose their artefactual quality. ${ }^{11}$ Scientific truths are contingent achievements and must be addressed in such a way as not to push out of the picture the singular quality of the practices that enable that achievement. Thus the success of certain kinds of experimental scientific practices stems from the very particular way in which the experimental invention invents "the power to confer on things the power of conferring on the experimenter the power to speak in their name", ${ }^{11}$ and not from some epistemological abstraction called 'the' scientific method. For Stengers the singular achievements of experimental science must not be transformed into a general model for rationality: to treat them in this way puts one at risk of knowing in advance the terms on which the adventure of enquiry must be understood. In this respect, critical recourse to concepts that are not attentive to the risks of generality, such as that of discourse, quickly adopt an ironic stance that is at odds with the humour that would be needed to establish what Stengers calls a 'shared perplexity' that would produce equality between those between whom it is shared. The ironist, always keen to unveil illusions, depends upon taking for granted the possibility that one can refer to some "more lucid and more universal power to judge that assures [the ironist's] difference from those being studied" (p. 66). ${ }^{11}$

It is this element of 'equality' between practices that really seems to be missing from the accounts of immunology that have been explored here. The 'aporia' of immunity uncovered by Esposito, for example, which creates confusion within the life sciences, is not something that is shared by the criticalhermeneutic philosopher (who can explain that confusion with reference to the complex constellation of meaning, the horizon of meaning, which 'unavoidably' frames any and every thought about risk, security and protection). With a diametrically opposed view of immunology, it is also missing Sloterdijk's work, for example. By presenting immunology as a clear and settled set of findings, the implication is that without the enlightening benefits of the findings of science, any other kind of knowledge practices that attempted to address culture are destined to remain hopelessly muddled and confused.

For the different kinds of critical research that we have considered, discourses of immunity evidently exhibit problematic connections with culture more broadly, yet such discussions do little to convey the uncertainties operative within immunology considered as a practice, and they do little to address the problems that they do disclose other than by referring that immunology to another court of judgement. Focusing on the more obviously problematic elements of immunological discourse is enormously illuminating. However, there are other elements of the conceptual frameworks of immunological research, which, on closer investigation, also pose problems. Kupiec and Sonigo have, for example, pointed out that the concept of 'stereospecificity' is a residue of the 'Aristotelianism' of biology, indicating another overlap between science and philosophy within immunology. ${ }^{29}$ However, it is as life scientists that they have made this claim, and indicated just how and why 'stereospecificity' is problematic, suggesting that factoring such insights into effective critique requires finding different ways of connecting research practices. ${ }^{29}$ Ultimately, the difficulty is that the kinds of conceptual '“shortcuts' one takes in generating one's close analysis of the discourses of immunity obviate the need to tackle what it is that one might not know oneself. In dissimulating what it does not know in this way, it may be that the different kinds of critical analysis addressed here share more with the object of their criticisms than they would like to allow. For a critical medical humanities to develop an approach to immunology that, in Stengers' words, would "[cause] the unknowns in the modern question to resonate" (p. 76) (28 $^{28}$ would demand working with life sciences research to subvert the polemical claim that one knows, where others merely believe.

Competing interests None declared.

Provenance and peer review Not commissioned; externally peer reviewed.

\section{REFERENCES}

1 Haraway D. Simians, cyborgs, and women: the reinvention of nature. London: Free Association Books, 1991

2 Martin E. Flexible bodies: tracking immunity in American culture from the days of polio to the age of aids. Boston, MA: Beacon Press, 1994.

3 David NA. The age of immunology: conceiving a future in an alienating world. Chicago, IL: The University of Chicago Press, 2003.

4 Cohen E. Immune Communities, Common Immunities. Social Text 94 26/1. 2008.

5 Anderson W, Warwick I. Intolerant bodies. A short history of autoimmunity. Baltimore, MA: Johns Hopkins University Press, 2014.

6 Luhmann N. Social systems. Stanford, CA: Stanford University Press, 1995.

7 Derrida J. Acts of religion. New York/London: Routledge, 2002.

8 Derrida J. Rogues: two essays on reason. Stanford, CA: Stanford University Press, 2005.

9 Esposito R. Immunitas. Cambridge: Polity, 2011.

10 Stengers I. La vierge et le neutrino. Paris: Les empêcheurs de penser en rond/Seuil, 2006.

11 Stengers I. The invention of modern science. Minneapolis, MN: University of Minnesota Press, 2000.

12 Chertok L, Stengers I. A critique of psychoanalytic reason: hypnosis as a scientific problem from Lavoisier to Lacan. Stanford, CA: Stanford University Press, 1992.

13 Silverstein AM. A history of immunology. New York, NY: Academic Press, 1989.

14 Tauber A. The immune self: theory or metaphor. Cambridge: Cambridge University Press, 1996.

15 Tauber A, Podolsky S. The generation of diversity. Clonal selection theory and the rise of cellular immunology. Cambridge, MA and London: Harvard University Press, 1997.

16 Mazumdar P. Species and specificity. An interpretation of the history of immunology. Cambridge: Cambridge University Press, 2002.

17 Tauber A, Chernyak L. Metchnikoff and the origins of immunology. From metaphor to theory. New York; Oxford: Oxford University Press, 1991.

18 Mather C. The angel of Bethesda. An essay upon the common Maladies of Mankind. Ann Arbord, Ml: University of Michigan Press, 1972.

19 Kendall M. Dying to live: how our bodies fight disease. Cambridge: Cambridge University Press, 1998

20 Nilsson L, Lindberg J. The body victorious: the illustrated story of our immune systems and other defenses of the human body. Delacorte Press, 1987.

21 Burnet FM. The integrity of the body. Cambridge: Cambridge University Press, 1963.

22 Haraway D. The High Cost of Information in Post-World War II Evolutionary Biology: Ergonomics, Semiotics, and the Sociobiology of Communication Systems. Philosophical Forum 13 1981-2.

23 Keating P, Cambrosio A. Biomedical platforms. Realigning the normal and the pathological in late twentieth century medicine. Cambridge, MA: MIT Press, 2003.

24 Jacob F. The logic of life: a history of heredity. London: Penguin, 1989.

25 Cooper M. Life as surplus: biotechnology and capitalism in the neoliberal era. Seattle, WA: University of Washington Press, 2008.

26 Cohen E. A body worth defending. Immunity, biopolitics, and the apotheosis of the modern body. Durham, NC and London: Duke University Press, 2009.

27 Sloterdijk P. You must change your life. Cambridge: Polity, 2013.

28 Stengers I. Cosmopolitics 1. Minneapolis, MN: University of Minnesota Press, 2010.

29 Kupiec J-J, Sonigo P. Ni Dieu ni gène. Pour une autre théorie de I'hérédité. Paris: Seuil, 2000 